worthy of discussion during clinical and health advisor consultations.

Disclosure No significant relationships.

\section{P326 SYNDEMIC PATTERNS OF RISK FOR SEXUALLY TRANSMITTED INFECTIONS}

${ }^{1}$ Ashley Hill*, ${ }^{2}$ Tamika Gilreath, ${ }^{3}$ Maria Perez-Patron, ${ }^{4}$ Brandie Taylor. ${ }^{1}$ Texas AandM University, College Station, USA; ${ }^{2}$ Texas AandM University, Transdisciplinary Center For Health Equity Research, College Station, USA; ${ }^{3}$ Texas AandM University, Epidemiology and Biostatistics, College Station, USA; ${ }^{4}$ Temple University, Epidemiology and Biostatistics, Philadelphia, USA

10.1136/sextrans-2019-sti.436

Background Syndemics theory proposes that diseases may cluster and intensify based on multiple interacting factors. Few studies have compared methods to identify syndemics related to sexually transmitted infection (STI) risk. The purpose of this study is to compare the use of a composite scoring method and latent class analysis to identify syndemics of STI risk.

Methods Youth were aged 18-25 who participated in the National Health and Nutrition Examination Survey, 2011$2014(\mathrm{~N}=1,803)$. Syndemic composite scoring was tabulated by an accumulation of indicators by gender, and latent class analysis (LCA) was conducted to extract classes of risk based on indicators reported by gender. The outcome, STIs, was defined as a determinant result for Chlamydia trachomatis, Herpes Simplex Virus type-2, or HIV. The odds of STI were calculated using the patterns of risk by sex adjusted for demographic and poverty indicators.

Results Composite score results suggest that males with an accumulation of 3 to 5 syndemic indicators (AOR: $2.10 \mathrm{CI}$ 95\% 1.0-4.2) and 6 or more indicators (AOR: 2.84 CI 95\% 1.2-6.7) had an increased odds of STI. Similarly, females with 6 or more indicators (AOR: 3.20 CI 95\% 1.7-6.0) had increased odds of STI. The LCA suggested that men with the highest probability of smoking and sexual risk behaviors were at increased odds of STI (AOR: 2.42 CI 95\% 1.1-5.4), while women exhibit a syndemic of depression, smoking, drug use and sexual risk behaviors (AOR: 2.19 CI 95\% 1.2-3.8).

Conclusion The co-occurrence of mental health,substance use and smoking were important indicators of STI risk in women. LCA was able to determine indicators that co-occurred in men and women and sexual risk behaviors that differed by gender, while the syndemic scoring show an accumulation of indicators increased STI risk.

Disclosure No significant relationships.

\section{P327 PATTERN OF SEXUALLY TRANSMITTED INFECTIONS IN THE INTERIOR PART OF SINDH PROVINCE OF PAKISTAN}

${ }^{1}$ Mour Khan*, ${ }^{2}$ Shahnawaz Bhutto, ${ }^{3}$ Nadia Agha, ${ }^{4}$ Erum Junejo. ${ }^{1}$ Shah Abdul Latif University and CMC Larkana, Sociology, Khairpur, Pakistan; ${ }^{2}$ Shah Abdul Latif University and CMC Larkana, Economics, Khairpur, Pakistan; ${ }^{3}$ Shah Abdul Latif University, Sociology, Khairpur, Pakistan; ${ }^{4}$ Chandka Medical College and SMBB Medical University, Dermatology, Larkana, Pakistan

\subsection{6/sextrans-2019-sti.437}

Background Sexual Transmitted infections (STls) are widespread in Pakistan and have not been fully documented. A hospital based prospective study was carried out to determine the incidence and clinical pattern of various types of STls in general population of Larkana division and its surrounding cities.

\section{Methods}

Patients and methods This study was conducted at male STD Clinic in the Department of Dermatology Shaheed Mohtarma Benazir Bhutto Medical University (SMBBMU) hospital Larkana. A total of 4288 cases were seen in this semi urban area. A structured questionnaire presenting the details of syndromic diagnosis was filled during the examination of each patient. For our ease and understanding, these patients were also separated on the basis of clinical and etiological grounds. Results Among 4288 patients, 3947 had the history of extra marital sexual contact and simultaneously had developed clinical signs of STls. Majority of patients had the history of heterosexual contact with different partners. According to syndromic diagnosis: 1930 patients had genital ulcer (including herpes genitals) with or without skin manifestations, 690 had urethral discharge, 431 had genital warts, 349 had lesions other than STls related, 304 had more than one syndrome, 193 had scrotal swelling, 46 had inguinal baboo, 3 were human immunodeficiency virus (HIV) positive and 1 had ophthalmia neonatorium.

Conclusion It is concluded that 5Tls are the growing concern and a public health problem in the central part of 5 indh province of this muslim state and syphilis exhibited the highest level of concentration followed by gonorrhea and so on. Community needs to be educated for adopting the safe sex measures to prevent the STls.

Disclosure No significant relationships.

\section{P328 SEXUAL HEALTH CARE: PROFESSIONAL DEVELOPMENT FOR RURAL PRACTITIONERS}

Siobhan Bourke*, Jane Tomany. University of Melbourne, Department of Rural Health Centre for Excellence in Rural Sexual Health, Wangaratta, Australia

\subsection{6/sextrans-2019-sti.438}

Background Rural doctors have limited accessible professional development, barriers include time, travel, expense and relief staffing issues. Sexual Health Care education opportunities were lacking, so we have provided online, free, accredited education for rural practitioners that was relevant to their practice. The online education modules, which are unique, use a rural lens when addressing sexual health care needs in practice in rural communities.

Methods The Centre for Excellence in Rural Sexual Health instigated the production of online learning modules. The first 8 were launched in 2016 and a further two have been launched since. Each module is evaluated by the participant upon completion. The modules cover practical topics in sexual health care ranging from sexual history taking, partner notification in a small community to avoiding assumptions in sexual health care.

Results 326 modules have been completed. The most popular modules were 'Introduction to rural sexual health care', 'Cornerstones of sexual health care' and 'STI treatment and management modules'. These modules are compulsory for a General Practitioner to complete if he or she is completing them as part of a large professional development activity (known as an Active Learning Module). The rest of the modules are free choice; with the most popular module being 
'Privacy and Confidentiality'. The learning objectives were met for the majority of participants. Different aspects of the modules - format, references, learning activities were rated from 1 (worst) to 5 (best) with all ratings ranging from 3 to 5 . Areas for improvement were video time length as some rural areas had difficulty with internet speed but the majority were perceived to be relevant to rural practice and the mode of learning acceptable for practitioners.

Conclusion The modules promote inquiry-based learning for adult learners and provide opportunity for rural doctors to critique and reflect on their own practice.

Disclosure No significant relationships.

\section{P329 STRESS, POST-TRAUMATIC STRESS DISORDER, AND SEXUAL AND REPRODUCTIVE HEALTH IN A NATIONALLY-REPRESENTATIVE SAMPLE OF US WOMEN}

Joy Scheidell*, Maria Khan. NYU School of Medicine, New York, USA

10.1136/sextrans-2019-sti.439

Background Examination of stress and post-traumatic stress disorder (PTSD) in relation to sexual and reproductive health $(\mathrm{SRH})$ is limited. Stress, potentially by impairing immune response and increasing risk-taking behavior, may influence risk of poor SRH. 'Weathering' effects from chronic stress exposure that accumulate over time may further heighten risk.

Methods Using Wave IV data on 7870 women (ages 24-34) in the National Longitudinal Study of Adolescent to Adult Health, we defined high stress as scores $\geq 6$ ( $75^{\text {th }}$ percentile) on the 4-item Perceived Stress Scale and PTSD as self-reported diagnosis by a healthcare provider; we categorized years since diagnosis as never, $\leq 2,3-5, \geq 6$. Women reported lifetime and past year sexually transmitted infection (STI) and pelvic inflammatory disease (PID) diagnoses, adverse pregnancy outcomes (miscarriage, ectopic/tubal pregnancy, stillbirth), and impaired fecundity (difficultly becoming/staying pregnant). We used modified Poisson regression to estimate sociodemographic-adjusted prevalence ratios (APR) and 95\% confidence intervals (CI).

Results Approximately 43\% reported high stress and 4\% PTSD ( $1 \% \leq 2$ years since diagnosis, $1 \% 3-5$ years, $2 \% \geq 6$ years). High stress was associated with past year bacterial STIs $(A P R=1.53,95 \% \mathrm{CI}: 1.13,2.09)$, unassociated with viral STIs, and weakly associated with adverse pregnancy outcomes $(\mathrm{APR}=1.24,95 \% \mathrm{CI}: 1.02,1.50)$ and impaired fecundity $(\mathrm{APR}=1.13$, 95\%CI: 0.98, 1.30). PTSD was also associated with lifetime viral STIs $(\mathrm{APR}=1.40,95 \% \mathrm{CI}$ : 1.06, 1.83) and PID (APR $=3.12,95 \% \mathrm{CI}: 1.59,6.12)$. Compared to women never diagnosed with PTSD, APRs for past year bacterial STIs were 2.66 (95\%CI: 1.28, 5.55) and 3.12 (95\%CI: $1.49,6.55)$ for women diagnosed $\leq 2$ years and $\geq 6$ years ago respectively, but not associated for women diagnosed 3-5 years ago.

Conclusion High 'global' perceived stress is associated with increased prevalence of poor SRH among women. Stronger associations were demonstrated in women with PTSD, particularly those with shorter and longer time since diagnosis, potentially suggesting both adverse acute and chronic stress responses.

Disclosure No significant relationships.

\section{P330 \\ THE SEXUAL AND REPRODUCTIVE HEALTH NEEDS OF HARD TO REACH GROUPS IN UGANDA}

Samuel Mukasa*, Peter Byansi. Uganda Martrys University, Health Sciences, Kampala, Uganda

\subsection{6/sextrans-2019-sti.440}

Background Inorder to achieve universal health coverage for all, the government of Uganda committed to advancing family planning for all during the FP2020 London Summit in July 2017. Despite efforts by Ministry of health (MOH) and Implementing partners (IPs) to implement programs that are complementary to static services, some communities remain hard to reach. Emerging New groups of nomads, balaro (Agago, Gulu, Apach). These don't return but settle in new scarcely populated areas, father children, acquire STI The Ike suffer from attacks from Kenya and Uganda, are isolated, not reached by SRHR services, have SRH needs. The Batwa, lived in forests but now displaced. Lost livelihood, Not integrating well with communities. Sexually exploited by communities due to myths. These groups remain hard to reach by due to factors like; stigma, geographical isolation, cultural beliefs, life style patterns and biological factors. There's been minimal change in SRH indicators, despite growing focus by IP (Kanungu, Kisoro, Rubanda)

Methods A qualitative design utilizing case study approach to qualitative inquiry was used Data collection was by; Document review Key informant interviews (KIIs) Focus group discussions (FGDs) Sampling for FGDs and KIIs was purposive with maximum variation Data collected was transcribed, analysed thematically and report generated

Results The key SRHR needs include; sexually transmitted infections, sexual and gender-based violence, family planning, female genital mutilation, limited delivery at health facilities, low ANC attendance and a high held role of TBAs in these communities. The most significant barriers to SRHR services include; extreme poverty, poor cultural beliefs, low literacy levels, alcohol abuse, language barriers, distance between the clients and available heath services.

Conclusion The SRHR needs are documented in the existing literature and not unique to hard to reach groups though of greter impacts among these groups. The most unique barrier to SRH services incude; language barrier, poverty and distance to existing health services

Disclosure No significant relationships.

\section{P331 QUANTITATIVE EVALUATION OF AN INNOVATION CONTEST TO ENHANCE A SEXUAL HEALTH CAMPAIGN IN CHINA}

${ }^{1}$ Ye Zhang ${ }^{*},{ }^{2}$ Songyuan Tang, ${ }^{3}$ Katherine Li, ${ }^{4}$ Lai Sze Tso, ${ }^{5}$ Barry Bayus, ${ }^{6}$ David Glidden, ${ }^{7}$ Bin Yang, ${ }^{8}$ He-Ping Zheng, ${ }^{9}$ Chongyi Wei, ${ }^{4}$ Joseph Tucker, ${ }^{4}$ Weiming Tang. ${ }^{1}$ Kirby Institution, UNSW, Sydney, Australia; ${ }^{2}$ Kunming Medical University, Kunming, China; ${ }^{3}$ Weill Cornell Medical College, New York, USA; ${ }^{4}$ UNC Project-China, Guangzhou, China; ${ }^{5}$ University of North Carolina, Chapel Hill, USA; ${ }^{6}$ University of California, San Francisco, USA; 'Guangdong Center for STD Control and Prevention, Guangzhou, China; ${ }^{8}$ Dermatology Hospital of Southern MedicalUniversity, Guangdong Center for STD Control and Prevention, Guangzhou, China; ${ }^{9}$ The State University of New Jersey, Rutgers, USA

\subsection{6/sextrans-2019-sti.441}

Background Crowdsourcing method is an excellent tool for developing tailored interventions to improve sexual health. We 